\title{
Efeitos da farinha de folhas de mandioca sobre a atividade das enzimas AST, ALT, FA e lipídios hepáticos de ratos Wistar
}

\author{
Effects of cassava leaves flour on the AST, ALT, ALP enzymes activity and hepatic lipids of Wistar rats
}

Daniela Séfora de $\mathrm{MELO}^{1 *}$, Angelita Duarte CORRÊA², Flávia Cristina Almeida MARCOS², Raimundo Vicente de SOUSA ${ }^{3}$, Celeste Maria Patto de ABREU², Custódio Donizete dos SANTOS ${ }^{2}$

\begin{abstract}
Resumo
Folhas de mandioca possuem substâncias como ligninas e saponinas que podem apresentar efeito hipolipidêmico. Todavia, um estudo recente relatou aumento no peso do fígado de ratos alimentados com dietas contendo farinha de folhas de mandioca (FFM - Manihot esculenta Crantz cv. Cacao), tornando-se necessário um estudo mais aprofundado dos efeitos desta farinha sobre os parâmetros hepáticos. Para este estudo, um ensaio biológico com 32 ratos machos Wistar foi conduzido por um período de 7 semanas, sendo os tratamentos: dieta controle e dietas contendo 5, 10 e 15\% de FFM. As dietas contendo FFM não apresentaram efeitos sobre as atividades das enzimas Aspartato Aminotransferase (AST) e Fosfatase Alcalina (FA), mas aumentaram significativamente a atividade da enzima alanina aminotransferase (ALT). O estudo histopatológico revelou vacuolização do citoplasma dos hepatócitos para todos os grupos. No entanto, a freqüência de animais com vacuolização acentuada foi superior nos grupos que receberam dietas com FFM, apresentando também maiores teores de lipídios e colesterol total hepáticos e maior relação peso fígado/peso corporal. Estes resultados indicam que os antinutrientes presentes nas folhas de mandioca, como taninos, cianeto e saponinas, podem ser responsáveis pela redução da função hepática nos animais alimentados com FFM.
\end{abstract}

Palavras-chave: folha de mandioca; saponina; polifenol; cianeto; rato Wistar.

\begin{abstract}
Cassava leaves contain substances such as lignins and saponins that can present the hypolipidemic effect. However, a recent study has reported an increase in liver weight of rats fed diet containing cassava leaves flour (CLF - Manihot esculenta Crantz cv. Cacao). Thus, a further study of the effect of this flour on the hepatic parameters is necessary. For the development of this study, a biological assay with 32 male Wistar rats was conducted for a period of 7 weeks with the following treatments: control diet and diets containing 5, 10, and 15\% of CLF. The diets containing CLF showed no effects on the Aspartate Aminotransferase (AST) and Alkaline Phosphatase (ALP) enzymes activity, but they significantly increased the Alanine Aminotransferase (ALT) enzyme activity. The histopathologic study showed hepatocytes cytoplasm vacuolization for all groups. However, the number of animals with sharp vacuolization was higher in the groups that received diets with CLF, which also showed higher levels of hepatic lipids, total cholesterol, and greater ratio liver weight / body weight. These results indicate that the antinutrients in the cassava leaves, such as tannins, cyanide, and saponins are probably responsible for the reduction in the hepatic function of animals fed with CLF.
\end{abstract}

Keywords: cassava leaf; saponin; polyphenol; cyanide; Wistar rat.

\section{Introdução}

A Farinha de Folhas de Mandioca (FFM) vem sendo utilizada na alimentação humana devido principalmente ao seu conteúdo de vitaminas e minerais. Todavia, as folhas de mandioca apresentam algumas substâncias consideradas antinutritivas, como cianeto, taninos, nitrato, ácido oxálico, saponinas, hemaglutinina e inibidores de tripsina (CORRÊA et al., 2004; WOBETO, 2003), contudo, substâncias como ligninas e saponinas também podem apresentar efeito hipolipidêmico (RAO, 1986; KENDALL, 1986). Melo et al. (2007) testaram a FFM em dietas para ratos, com o objetivo de reduzir os níveis de colesterol sangüíneo. Os autores avaliaram o efeito da FFM sobre o colesterol total, triacilgliceróis, colesterol na fração
HDL, colesterol nas frações LDL + VLDL e peso do fígado de ratos. Os lipídios sangüíneos não apresentaram alteração, mas em contrapartida ocorreu um aumento significativo no peso do fígado de todos os grupos que receberam dieta contendo a FFM. Portanto, torna-se necessário um estudo mais aprofundado dos efeitos desta farinha sobre parâmetros hepáticos, e possivelmente caracterizá-la como um complemento benéfico, ou não, em dietas alimentares.

No presente trabalho estudou-se o efeito da adição de FFM em dietas hipercolesterolêmicas, sobre algumas enzimas do sangue e lipídios hepáticos de ratos Wistar.

Recebido para publicação em 2/4/2007

Aceito para publicação em 18/4/2008 (002402)

${ }^{1}$ Centro Federal de Educação Tecnológica da Bahia - CEFET-BA, Unidade de Porto Seguro, BR 376, Km 5, CEP 45810-000, Porto Seguro - BA, Brasil,

E-mail: seforas@hotmail.com

${ }^{2}$ Departamento de Química - DQI, Universidade Federal de Lavras - UFLA, CP 3037, CEP 37200-000, Lavras - MG, Brasil, E-mail: angelita@ufla.br

${ }^{3}$ Departamento de Medicina Veterinária - DMV, Universidade Federal de Lavras - UFLA, Lavras - MG, Brasil

${ }^{*}$ A quem a correspondência deve ser enviada 


\section{Material e métodos}

\subsection{Farinha de folhas de mandioca (FFM)}

Folhas maduras de mandioca (Manihot esculenta Crantz cv.Cacao) foram colhidas aleatoriamente aos 12 meses de idade da planta, no mês de dezembro, e transportadas para o Laboratório de Bioquímica do Departamento de Química da Universidade Federal de Lavras. As folhas foram lavadas em água corrente e água destilada e, em seguida, secas em estufa ventilada à temperatura de 30 a $35^{\circ} \mathrm{C}$, por 48 horas e, em seguida, trituradas em moinho. A FFM foi armazenada em recipiente de plástico e estocada em geladeira, até as análises e uso nas dietas experimentais. As análises foram realizadas em triplicata.

As dosagens de umidade, extrato etéreo, proteína bruta (utilizando-se o fator de conversão 6,25) e cinza na FFM e nas dietas experimentais, foram determinadas segundo a AOAC (1995). A Fibra Detergente Neutro (FDN) e a lignina foram quantificadas pelo método proposto por Van Soest, descrito por Silva (1990). O Extrato Não Nitrogenado (ENN) foi calculado por diferença.

A saponina foi quantificada segundo Baccou et al. (1977), os polifenóis de acordo com Goldstein e Swain (1963) e o cianeto segundo a metodologia descrita por Corrêa et al. (2002). A digestibilidade protéica in vitro foi medida segundo Akeson e Stahmann (1964).

\subsection{Ensaio biológico}

Foram utilizados 32 ratos, machos albinos (Rattus novergicus), da linhagem Wistar, provenientes do Biotério do Departamento de Medicina Veterinária da Universidade Federal de Lavras, em fase de crescimento e com peso médio inicial de $129,08 \pm 22,26 \mathrm{~g}$. Os animais foram mantidos em gaiolas individuais, em sala com temperatura de $25 \pm 3{ }^{\circ} \mathrm{C}$ (ciclo dia: noite 12 horas) e com acesso à ração e água ad libitum, por um período de 49 dias.

Os animais foram pesados e distribuídos aleatoriamente em 4 grupos, com oito animais por grupo, constituindo os tratamentos: controle - dieta padrão e três outros grupos com dietas contendo 5, 10 e 15\% de FFM. Em todos os grupos as dietas continham $1 \%$ de colesterol, eram isocalóricas e apresentavam o mesmo teor de fibras e proteína digestível. As dietas experimentais (Tabela 1) foram preparadas de acordo com AIN-93G (1993).

O uso de $1 \%$ de colesterol foi devido a este estudo ser uma continuação de um experimento anteriormente reportado por nosso grupo, em que o uso da dieta hipercolesterolêmica foi necessário (MELO et al., 2007).

Os teores de fibra e proteína digestível encontrados na FFM foram descontados nos teores de celulose e caseína adicionados às dietas. Desta forma, com o progressivo aumento na porcentagem de FFM nas dietas, as porcentagens de caseína e celulose foram menores e para que ao final da elaboração as dietas apresentassem todas $100 \mathrm{~g}$, foi necessária a adição do caolim. Assim, a dieta sem FFM recebeu a maior porcentagem de caolim e nas dietas com 5, 10 e $15 \%$ a porcentagem de caolim foi progressivamente menor.

O consumo de ração e o peso dos animais foram acompanhados semanalmente, calculando-se assim o consumo médio diário (CMD), o Ganho de peso Médio Diário (GMD) e o Coeficiente de Eficiência Alimentar (CEA), este último calculado pela divisão do GMD pelo CMD.

Ao término do experimento, os animais foram deixados em jejum, por cerca de 12 horas e, em seguida, foram anestesiados com éter etílico por inalação em câmara fechada. O sangue foi retirado dos grandes vasos abdominais e, em seguida, centrifugado para obtenção do soro e analisado quanto à atividade das enzimas AST, ALT e FA, utilizando-se o kit enzimático-colorimétrico Bioclin ${ }^{\circledast}$.

O fígado foi retirado por meio de laparotomia mediana, lavado em solução salina $0,9 \%$, pesado e estocado a $-25{ }^{\circ} \mathrm{C}$ para posteriores análises de umidade, extrato etéreo, Colesterol Total (CT) e estudo histopatológico. As análises de umidade e de extrato etéreo foram determinadas utilizando-se as metodologias propostas pela AOAC (1995). Para a quantificação de colesterol total as amostras de fígado secas e trituradas foram submetidas à extração lipídica com clorofórmio e metanol (2:1), conforme Folch et al. (1957), e a dosagem foi feita pelo método da colesterol oxidase, utilizando-se o kit enzimático-colorimétrico Bioclin ${ }^{\circledast}$. Para o estudo histopatológico, um fragmento de fígado de cada rato foi fixado em formalina $10 \%$. Os fragmentos foram embebidos em parafina, seccionados ( $5 \mathrm{~mm}$ ) e corados com hematoxilina e eosina (método HE). As lâminas foram avaliadas em microscópio e identificadas quanto à presença de esteatose hepática (infiltração gordurosa) com lesão leve (+), moderada $(++)$ ou acentuada $(+++)$.

O delineamento estatístico foi inteiramente casualizado, com quatro tratamentos e oito repetições, representando cada animal uma parcela experimental. Procedeu-se à análise de

Tabela 1. Composição das dietas experimentais (g.100 g-1).

\begin{tabular}{|c|c|c|c|c|}
\hline \multirow[t]{2}{*}{ Ingredientes } & \multicolumn{4}{|c|}{ Grupos } \\
\hline & Controle & $5 \%$ FFM & $10 \%$ FFM & $15 \%$ FFM \\
\hline Amido & 40 & 40 & 40 & 40 \\
\hline Caseína $^{1}$ & 20 & 19,5 & 19 & 18,5 \\
\hline Sacarose & 10 & 10 & 10 & 10 \\
\hline Óleo & 10 & 10 & 10 & 10 \\
\hline Celulose & 5 & 3,5 & 2 & 0,5 \\
\hline Mistura mineral & 3,5 & 3,5 & 3,5 & 3,5 \\
\hline Mistura vitamínica & 1 & 1 & 1 & 1 \\
\hline Metionina & 0,5 & 0,5 & 0,5 & 0,5 \\
\hline Colesterol & 1 & 1 & 1 & 1 \\
\hline Caolim & 9 & 6 & 3 & 0 \\
\hline FFM & 0 & 5 & 10 & 15 \\
\hline Total & 100 & 100 & 100 & 100 \\
\hline kcal.100 g $\mathrm{g}^{-1}$ & 358,00 & 358,24 & 358,44 & 358,64 \\
\hline Fibra $^{2}$ & 5,00 & 4,83 & 4,65 & 4,47 \\
\hline Proteína digestível $^{2}$ & 15,00 & 15,05 & 15,11 & 15,16 \\
\hline Proteína bruta & 15 & 16,11 & 17,23 & 18,35 \\
\hline
\end{tabular}

${ }^{1}$ Contendo $75 \%$ de proteína bruta; $\mathrm{e}^{2}$ os teores de fibra (FDN - 26,50 g. $100 \mathrm{~g}^{-1}$ ) e proteína digestível (proteína bruta - 29,86 g.100 g-1 e digestibilidade protéica - 28,88\%) encontrados na FFM foram descontados nos teores de celulose e caseína, respectivamente, para cada dieta. 
variância a 5\% de probabilidade, para a determinação do valor de F. Para F significativo, utilizou-se o teste de Scott-Knott a 5\% de probabilidade para a comparação entre as médias.

\section{Resultados e discussão}

\subsection{Farinha de folhas de mandioca}

Os dados de composição centesimal da FFM são apresentados na Tabela 2. O teor de proteína bruta, extrato etéreo e cinza da FFM analisada estavam dentro da faixa de variação relatada em outros trabalhos, para as folhas de outras cultivares de mandioca (CARVALHO et al., 1986; CORRÊA et al., 2004; MADRUGA; CÂMARA, 2000). No entanto, o teor de FDN foi relativamente inferior aos encontrados por Reed et al. (1982) e Corrêa et al. (2004), ou seja, 32,82 e 35,40 g.100 g-1 MS, respectivamente.

Na Tabela 3 são mostrados os teores de saponinas, polifenóis, cianeto e digestibilidade protéica in vitro da FFM. O teor de saponinas na FFM foi superior ao encontrado por Wobeto (2003), que analisando diferentes cultivares aos 12 meses de idade da planta, encontrou valores variando de 1,74 a $4,41 \mathrm{~g} 100 \mathrm{~g}^{-1} \mathrm{MS}$. O método utilizado para ambos os trabalhos foi o mesmo, desta forma, a diferença observada provavelmente é devido à cultivar analisada, entre outros fatores. Já os teores de polifenóis e a digestibilidade protéica in vitro estavam dentro da faixa de variação encontrada na literatura para diferentes cultivares e processamentos (CORRÊA et al. 2004; FONSECA, 1996; PADJAMA, 1989; WOBETO, 2003).O teor de cianeto na FFM foi superior aos teores encontrados por Corrêa et al. (2002), na cultivar Baiana, para folhas secas em estufa a 30 e $40^{\circ} \mathrm{C}\left(36,22\right.$ e $56,46 \mathrm{mg} \cdot 100 \mathrm{~g}^{-1} \mathrm{MS}$, respectivamente) e aos encontrados por Wobeto (2003), para diferentes cultivares e idades da planta e folhas secas à sombra (12,38 a 35,02 mg.100 g ${ }^{-1}$ MS). No entanto, Ravindran e Ravindran (1988) encontraram para folhas maduras secas ao sol e, em seguida, em estufa a $60^{\circ} \mathrm{C}$ por 24 horas, valores superiores (780 mg.100 g ${ }^{-1} \mathrm{MS}$ ). Estas variações devem-se, provavelmente, às diferenças genéticas entre as cultivares, às idades da planta, à fertilidade do solo, e às formas de secagem das folhas.

Tabela 2. Composição centesimal da Farinha de Folhas de Mandioca (FFM).

\begin{tabular}{lc}
\hline Constituintes & $\mathrm{FFM}^{1}\left(\mathrm{~g} \cdot 100 \mathrm{~g}^{-1}\right)$ \\
\hline Umidade $^{2}$ & $8,31 \pm 0,04$ \\
Extrato etéreo & $9,20 \pm 0,03$ \\
Proteína bruta & $29,86 \pm 0,10$ \\
Fibra $\left(\mathrm{FDN}^{3}\right)$ & $26,50 \pm 2,61$ \\
Cinzas & $6,15 \pm 0,52$ \\
\hline
\end{tabular}

${ }^{1}$ Médias de três determinações \pm desvio padrão; ${ }^{2}$ Umidade das folhas frescas de mandioca: $67,93 \pm 0,06$ g.100 g ${ }^{-1} ; e^{3} \mathrm{FDN}$ - fibra detergente neutro.

Tabela 3. Fatores antinutricionais e digestibilidade protéica in vitro da Farinha de Folhas de Mandioca (FFM).

\begin{tabular}{lc}
\hline \multicolumn{1}{c}{ Constituintes } & $\mathrm{FFM}^{1}$ \\
\hline Saponinas & $1,07 \pm 0,09\left(\mathrm{~g} \cdot 100 \mathrm{~g} \mathrm{~g}^{-1} \mathrm{MS}\right)$ \\
Polifenóis & $4,72 \pm 0,64\left(\mathrm{~g} \cdot 100 \mathrm{~g} \mathrm{~g}^{-1} \mathrm{MS}\right)$ \\
Cianeto & $123,64 \pm 13,42\left(\mathrm{mg} .100 \mathrm{~g}^{-1} \mathrm{MS}\right)$ \\
Digestibilidade protéica in vitro & $28,88 \pm 0,18(\%)$ \\
\hline${ }^{1}$ Médias de três determinações \pm desvio padrão.
\end{tabular}

\subsection{Ensaio biológico}

\section{Dietas e variáveis de desempenho}

A adição da quantidade máxima de 15\% de FFM usada nas dietas experimentais foi baseada no estudo feito por Ortega-Flores et al. (2003), que utilizaram a FFM como fonte protéica. Eles empregaram três níveis de FFM: 12,$5 ; 25$ e $50 \mathrm{~g}$ por $100 \mathrm{~g}$ da dieta. Os resultados mostraram que apenas a dieta com 12,5 g de FFM não apresentou redução significativa, quando comparados ao grupo controle, do Coeficiente de Eficiência Alimentar (CEA), ganho de peso médio diário (GMD) e Consumo Médio Diário (CMD). Portanto, valores próximos a $12,5 \mathrm{~g}$ de FFM por $100 \mathrm{~g}$ da dieta não trariam prejuízos para o desenvolvimento dos animais.

O CMD, GMD e CEA para os grupos com dietas controle e contendo 5, 10 e 15\% de FFM estão representados na Tabela 4. As análises de variância, utilizando-se o esquema de parcelas subdivididas no tempo, não mostraram diferenças significativas a $1 \%$ de probabilidade, pelo teste $\mathrm{F}$, para cada tratamento.

Ross e Enriquez (1969), avaliando o valor nutritivo de FFM adicionada às dietas nas proporções $0,3,5,10,15 \mathrm{e} 20 \% \mathrm{em}$ pintos, não encontraram diferenças significativas para o ganho de peso até a proporção 15\% de FFM nas dietas. Ortega-Flores et al. (2003a) observaram que não houve diferenças significativas para tratamentos sobre o consumo da ração, ganho de peso e CEA quando 12,5 g de FFM. $100 \mathrm{~g}^{-1}$ da dieta, correspondente a 2,5\% como fonte de proteína, foram adicionados em dietas para ratos. Estes dados estão de acordo com os encontrados neste trabalho.

Na Figura 1 está representada a curva de crescimento médio dos ratos tratados por 7 semanas com dieta controle e contendo 5, 10 e 15\% de FFM. A análise de variância para os pesos dos animais no decorrer da fase experimental (curva de crescimento) mostrou diferença significativa, a $1 \%$ de probabilidade, pelo teste $F$ apenas para o tempo.

Observa-se que, ao final do experimento, os animais alcançaram aproximadamente $50 \%$ do peso adulto. A variação do ganho de peso com o passar do tempo se reduz até o rato alcançar a fase adulta.

Atividades de aspartato aminotransferase, alanina aminotransferase, fosfatase alcalina e análises no fígado

$\mathrm{Na}$ Tabela 5 estão apresentados os valores médios para as atividades das enzimas FA, AST e ALT no soro. A análise de variância mostrou-se não significativa para as enzimas FA e AST e significativa para a ALT.

Tabela 4. CMD, e GMD e CEA dos ratos com as dietas, durante a fase experimental.

\begin{tabular}{cccc}
\hline Dietas $^{1}$ & CMD $(\mathrm{g})$ & GMD $(\mathrm{g})$ & CEA \\
\hline Controle & 14,92 & 2,97 & 0,187 \\
$5 \%$ FFM & 15,01 & 2,93 & 0,198 \\
$10 \%$ FFM & 14,86 & 2,92 & 0,198 \\
$15 \%$ FFM & 14,73 & 2,93 & 0,204 \\
\hline
\end{tabular}

${ }^{1}$ Controle = dieta padrão e dietas contendo 5, 10 e 15\% de FFM, todas com $1 \%$ de colesterol; $\mathrm{MD}$ = consumo médio diário; $\mathrm{GMD}$ = ganho de peso médio diário; $\mathrm{e}$ CEA = coeficiente de eficiência alimentar. 
A enzima AST é uma enzima encontrada em maior quantidade nas mitocôndrias, cerca de $80 \%$, e não é liberada tão rápido como a ALT, que é uma enzima puramente citosólica. A AST está presente em altas concentrações em um grande número de tecidos, como coração, fígado, músculo esquelético, rins e pâncreas. A ALT é primariamente limitada ao citosol dos hepatócitos, é considerada um indicador altamente sensível de dano hepatocelular e, dentro de certos limites, pode fornecer uma taxa quantitativa do grau de danificação sofrido pelo fígado (AL-HABORI; STAHMANN, 2002). Dessa forma, o aumento apenas na atividade da enzima ALT, para os grupos de animais alimentados com dietas contendo FFM, deve-se provavelmente a uma lesão dos hepatócitos dos fígados destes animais, não sendo grave o bastante para provocar o aumento também da enzima AST.

Hervás et al. (2003) estudaram a toxicidade de extratos de taninos do vegetal Quebrancho, em cabras, nas proporções $0 ; 0,5 ; 1,5$ e $3 \mathrm{~g}$ de tanino/ $\mathrm{kg}$ do peso corporal, administrado intra-ruminalmente uma vez ao dia, por um período de 21 dias. As atividades das enzimas FA e AST não sofreram alterações em todos os níveis de taninos. Já a atividade da ALT aumentou significativamente para o grupo que recebeu a dose $1,5 \mathrm{~g}$ de tanino/kg de peso corporal. Comparando-se os teores de taninos ministrados às cabras com os teores de polifenóis ingeridos diariamente pelos ratos: 0,$148 ; 0,296$ e $0,444 \mathrm{~g}$ de polifenóis/kg de peso, para as dietas com 5, 10 e 15\% de FFM, respectivamente,

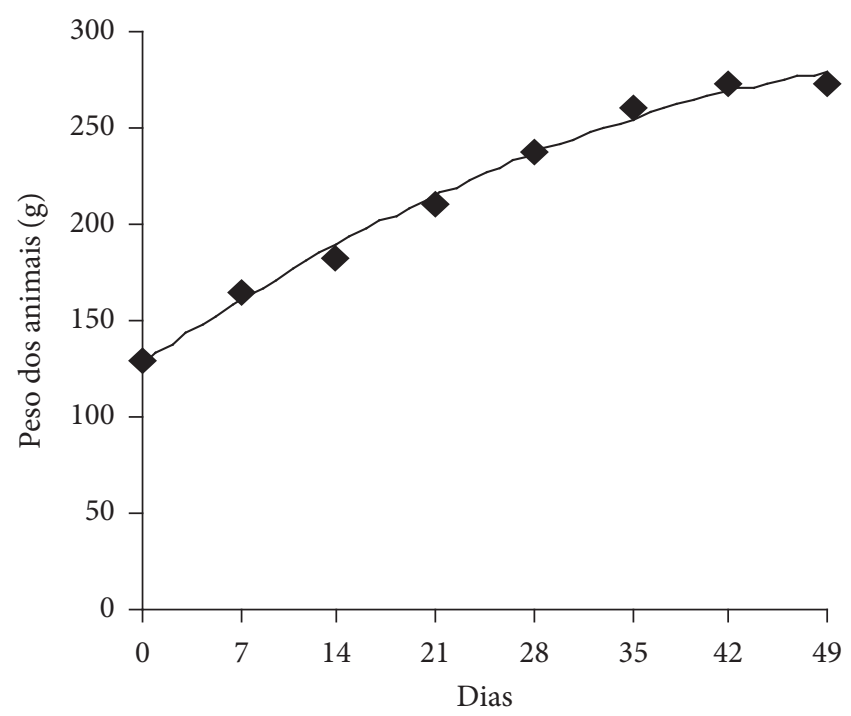

Figura 1. Curva de crescimento médio dos ratos com as dietas durante a fase experimental.

Tabela 5. Atividades de enzimas ${ }^{1}$ no sangue dos ratos, após 7 semanas com as dietas experimentais.

\begin{tabular}{lccc}
\hline \multicolumn{1}{c}{ Dietas $^{2}$} & FA $\left(\mathrm{U} \cdot \mathrm{mL}^{-1}\right)$ & AST $\left(\mathrm{U} \cdot \mathrm{mL}^{-1}\right)$ & ALT $\left(\mathrm{U} \cdot \mathrm{mL}^{-1}\right)$ \\
\hline Controle & 62,56 & 133,62 & $42,21 \mathrm{a}$ \\
$5 \%$ FFM & 71,45 & 149,62 & $89,08 \mathrm{~b}$ \\
$10 \%$ FFM & 61,30 & 141,20 & $78,91 \mathrm{~b}$ \\
$15 \%$ FFM & 56,50 & 144,28 & $69,94 \mathrm{~b}$ \\
\hline
\end{tabular}

${ }^{1}$ Letras diferentes na coluna indicam que as médias diferem entre si, pelo teste Scott-Knott ( $\mathrm{p} \leq 0,05) ;{ }^{2}$ Controle - dieta padrão e dietas contendo 5, 10 e 15\% de FFM, todas com $1 \%$ de colesterol; $\mathrm{FA}$ = fosfatase alcalina; $\mathrm{AST}=$ asparatato aminotransferase; $\mathrm{e}$ ALT = alanina aminotransferase. observa-se que os teores de polifenóis ingeridos pelos ratos foram inferiores. Como o período experimental deste estudo foi maior, pode ser que os taninos na FFM tenham contribuído para a maior atividade da enzima ALT.

Okafor et al. (2002) investigaram os efeitos bioquímicos da exposição ocupacional e dietária do cianeto, a partir do processamento em grande escala e ingestão de mandioca, em humanos. Pessoas envolvidas no processamento de mandioca por mais de seis meses e consumidores freqüentes e infreqüentes de mandioca foram usados para um estudo de caso. Ocorreu um aumento em mais de $10 \%$ acima do normal de atividade da AST em $40 \%$ dos processadores; no entanto, esta diferença não foi significativa. As atividades de ALT e FA ficaram dentro dos valores normais em todos os casos estudados. No presente trabalho, o cianeto das FFM e demais componentes, no período de 7 semanas, não provocaram diferenças significativas nas atividades das enzimas AST e FA.

Para verificar possíveis danos hepatocelulares causados por substâncias tóxicas presentes na FFM, fez-se também o estudo histopatológico, complementando-se os dados obtidos nas análises enzimáticas.

O estudo histopatológico revelou vacuolização do citoplasma dos hepatócitos, vista predominantemente na região perilobular, para todos os grupos. No entanto, a freqüência de animais com vacuolização acentuada foi superior nos grupos que receberam dietas com FFM (Figura 2). O acúmulo intracelular de água também produz vacúolos no citoplasma dos hepatócitos, mas o menor teor de umidade para os grupos com dieta contendo FFM e o maior teor de extrato etéreo indicam a ocorrência de degeneração gordurosa nos hepatócitos.

Nas fotos da Figura 3 observa-se a vacuolização do citoplasma dos hepatócitos para cada nível de intensidade, leve (+), moderada $(++)$ e acentuada $(+++)$.

A vacuolização ou degeneração dos hepatócitos (esteatose hepática) ocorre todas as vezes que um agente interfere no metabolismo dos ácidos graxos da célula, aumentando sua síntese ou dificultando sua utilização, transporte ou excreção (BRASILEIRO FILHO, 2004).

Nos estados de hipóxia, há redução da síntese de ATP. A hipóxia pode ser causada pelo cianeto, o qual se liga ao $\mathrm{Fe}^{3+}$ da ci-

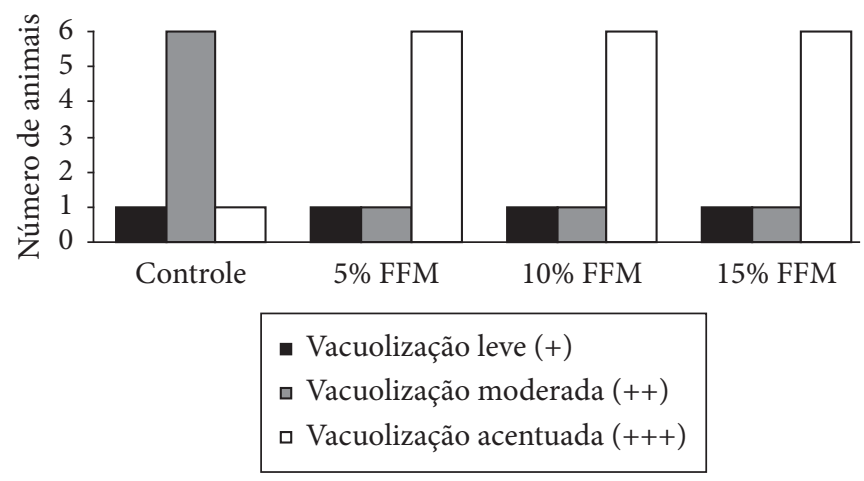

Figura 2. Distribuição das lesões observadas na análise histopatológica do fígado dos ratos, após 7 semanas de experimento. 
tocromo oxidase e inibe a etapa citocromo a-citocromo a, interrompendo o metabolismo oxidativo (MIDIO; MARTINS, 2000). Nesses casos, a esteatose decorre, em boa parte, do aumento da síntese de ácidos graxos a partir do excesso de acetil-CoA, cuja oxidação no ciclo de Krebs está diminuída. Esses ácidos graxos encontram grande quantidade de glicerolfosfato, originado da glicólise acelerada pela redução da síntese de ATP e formam os triacilgliceróis (TAG), que se acumulam no citoplasma (BRASILEIRO FILHO, 2004). Este seria um mecanismo proposto para o acúmulo de lipídios hepáticos nos ratos alimentados com folhas de mandioca, as quais apresentaram teores de cianeto considerados elevados.

Sousa et al. (2002) estudaram o efeito da exposição prolongada (15 dias) de cianeto de potássio em ratos nas doses 0,$12 ; 0,36 ; 1,20$ e $3,60 \mathrm{mg}$ de $\mathrm{CN}^{-} / \mathrm{kg}$ de peso corporal/dia, adicionado à água. Uma redução significativa no ganho de peso

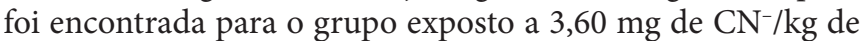
peso corporal/dia quando comparado ao controle. $\mathrm{O}$ estudo histopatológico revelou degeneração dos hepatócitos para os

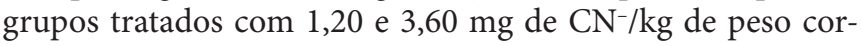
poral/dia. Considerando-se o teor de cianeto quantificado na FFM (113,37 mg. $\left.100 \mathrm{~g}^{-1}\right)$ e ainda, que cada animal ingeriu, em média, $15 \mathrm{~g}$ de dieta/dia e pesou, em média, $216 \mathrm{~g}$, eles estariam

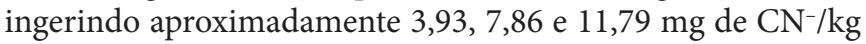
de peso corporal/dia, valores significativamente superiores aos estudados por Sousa et al. (2002). Considerando-se ainda a dose
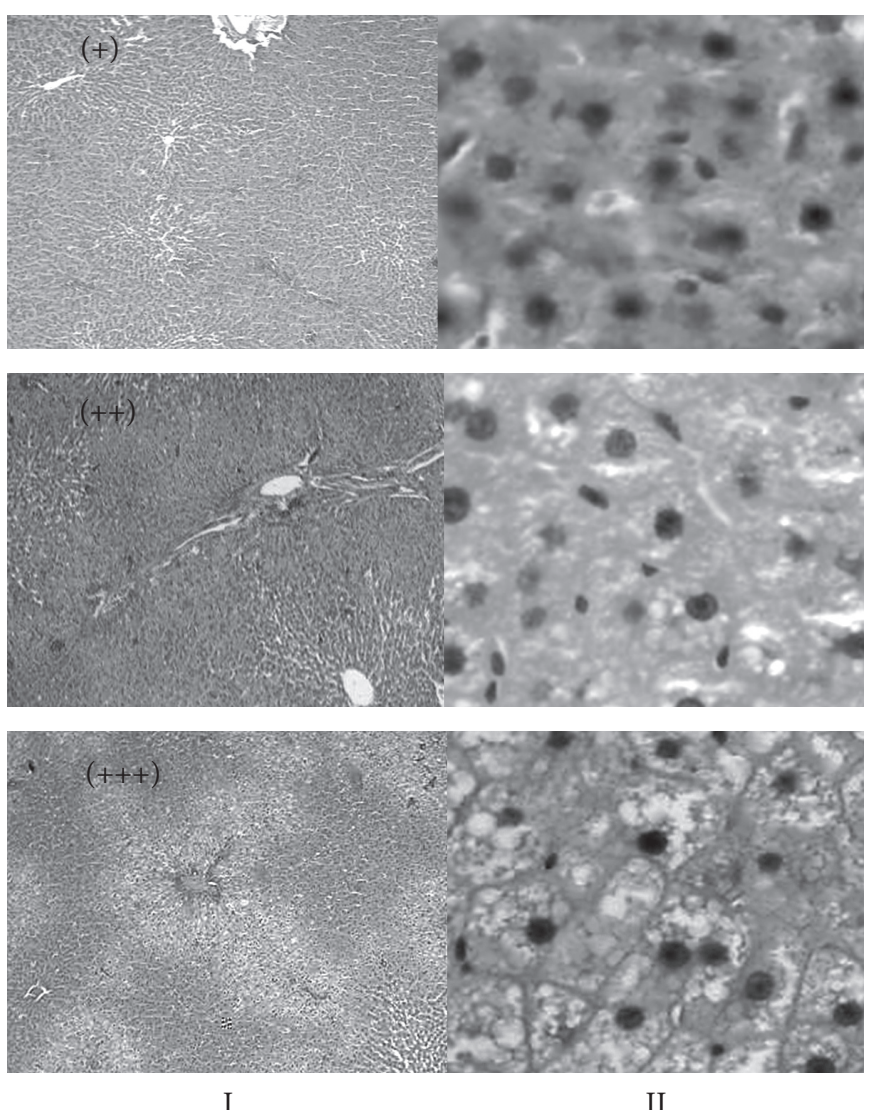

Figura 3. Vacuolização do citoplasma dos hepatócitos para cada nível de intensidade; leve $(+)$; moderada $(++)$ e acentuada $(+++)$; corados com hematoxilina e eosina; 40x (I); e 400x (II). letal $\left(\mathrm{DL}_{50}\right)$ de cianeto por via oral, a qual varia de 0,5 a $3 \mathrm{mg} \cdot \mathrm{kg}^{-1}$ de peso corporal (WOGAN; MARLETTA, 1993) os valores ingeridos pelos ratos são também superiores. Possivelmente, o cianeto da FFM apresentou o mesmo efeito hepatotóxico reportado por Sousa et al. (2002), sem, contudo, interferir no ganho de peso dos animais.

Na Tabela 6 são apresentados os teores médios de umidade, extrato etéreo, colesterol total e relação peso do fígado seco/peso corporal. Comparando-se a dieta controle com as dietas contendo FFM, verificou-se que a dieta controle foi significativamente diferente das demais. Ela apresentou maior teor de umidade e menores teores de lipídios e colesterol total e menor relação peso fígado/peso corporal.

O maior teor de extrato etéreo nos fígados dos grupos que receberam FFM confirmam os resultados obtidos no estudo histopatológico e nas análises enzimáticas, cuja presença dos glicosídeos cianogênicos pode ter sido responsável pelo maior acúmulo de TAG neste órgão.

Witthawaskul et al. (2003) estudaram a toxicidade subaguda de saponinas isoladas de Schefflera leucantha em ratos, em uma dose oral de $1.000 \mathrm{mg} . \mathrm{kg}^{-1}$ de peso corporal/dia, por um período de 14 dias. Os resultados mostraram aumento no peso do fígado e na atividade das enzimas ALT, AST e FA no grupo tratado com saponina quando comparado ao grupo controle. Os autores concluíram que as saponinas têm um impacto direto sobre as funções do fígado e que uma avaliação adicional de toxicidade crônica é recomendada. Considerando a quantidade de saponinas na FFM, 980 mg. $100 \mathrm{~g} \mathrm{~g}^{-1}$, as dietas com 5, 10 e 15\% de FFM continham 49, 98 e 147 mg de saponina/100 g, respectivamente. Se cada rato ingeriu aproximadamente $15 \mathrm{~g}$ da dieta/dia e pesava, em média, $216 \mathrm{~g}$, a dose de saponinas ingerida foi de 34,03, 68,06 e 102,08 mg. $\mathrm{kg}^{-1} \mathrm{de}$ peso corporal/dia, respectivamente. Quando se compara a quantidade de saponinas da dieta com 15\% de FFM com a quantidade de saponinas ingerida no trabalho citado acima, constata-se que ela é cerca de 10 vezes menor. Como houve uma grande diferença no tempo de duração dos experimentos, 14 e 49 dias, sugere-se que uma das causas para o aumento no peso do fígado e atividade da enzima ALT, nos grupos alimentados com FFM, pode ser devido às saponinas, cuja diferença nas quantidades foi compensada pelo maior tempo de exposição à substância.

De acordo com as comparações realizadas entre outros estudos e os resultados do presente trabalho, pode-se dizer que os antinutrientes presentes nas folhas de mandioca, como taninos, cianeto e saponinas, parecem ser responsáveis pela redução da função hepática nos animais alimentados com FFM.

Tabela 6. Teores médios ${ }^{1}$ de umidade, Extrato Etéreo (EE), Colesterol Total (CT) no fígado e relação Peso do Fígado (PF) seco/peso corporal (PC).

\begin{tabular}{lcccc}
\hline Dietas $^{2}$ & $\begin{array}{c}\text { Umidade } \\
\text { g.100 g }\end{array}$ & $\begin{array}{c}\text { EE } \\
\text { g.100 g-1 MS }\end{array}$ & $\begin{array}{c}\text { CT } \\
\text { g. } 100 \mathrm{~g}^{-1} \mathrm{MS}\end{array}$ & PF seco/PC \\
\hline Controle & $62,65^{\mathrm{b}}$ & $34,41^{\mathrm{a}}$ & $27,66^{\mathrm{a}}$ & $1,067^{\mathrm{a}}$ \\
$5 \% \mathrm{FFM}$ & $57,51^{\mathrm{a}}$ & $49,32^{\mathrm{b}}$ & $34,71^{\mathrm{b}}$ & $1,517^{\mathrm{b}}$ \\
$10 \% \mathrm{FFM}$ & $56,49^{\mathrm{a}}$ & $53,24^{\mathrm{b}}$ & $37,43^{\mathrm{b}}$ & $1,592^{\mathrm{b}}$ \\
$15 \%$ FFM & $59,56^{\mathrm{a}}$ & $44,29^{\mathrm{b}}$ & $34,95^{\mathrm{b}}$ & $1,419^{\mathrm{b}}$ \\
\hline
\end{tabular}

${ }^{1}$ Letras diferentes na coluna indicam que as médias diferem entre si pelo teste Scott- Knott ( $\mathrm{p} \leq 0,05) ; \mathrm{e}^{2}$ Controle - dieta padrão e dietas contendo 5, 10 e $15 \%$ de FFM, todas com $1 \%$ de colesterol. 


\section{Conclusões}

Dietas isocalóricas contendo até 15\% de FFM e 1\% de colesterol, em que a proteína digestível e as fibras foram corrigidas, não apresentam efeitos significativos sobre o desenvolvimento dos animais (CEA, GMD e CMD).

Todavia a adição de FFM, cultivar Cacao, à dieta animal, não deve ser indicada, uma vez que pode levar ao acúmulo de lipídios no fígado e, conseqüentemente, ao desenvolvimento de esteatose hepática. Da mesma forma, o consumo humano desta farinha, de forma contínua, e em quantidades elevadas, não é indicado, podendo levar à toxicidade crônica atribuída ao consumo de pequenas doses de cianeto, polifenóis e saponinas em intervalos de tempo longos.

\section{Agradecimentos}

Agradecemos ao CNPq e à FAPEMIG pela concessão das bolsas de Mestrado e Iniciação Científica.

\section{Referências bibliográficas}

AKESON, W. R.; STAHMANN, M. A. A pepsin pancreatin digest index of protein quality evaluation. Journal of Nutrition, v. 83, p. 257-261, 1964.

AL-HABORI, M. et al. Toxicological evaluation of Catha edulis leaves: a long term feeding experiment in animals. Ethno-Pharmacology, v. 83 , p. $209-217,2002$.

ASSOCIATION OF OFFICIAL ANALYTICAL CHEMISTS. Official methods of analysis of the Association of the Analytical Chemists. 16 ed. Washington, 1995.

BACCOU, J. C.; LAMBERT, F.; SAUVAIRE, Y. Spectrometric method for the determination of total steroidal sapogenin. Analyst, v. 102, n. 5, p. 458-465, 1977.

BRASILEIRO FILHO, G. Bogliolo patologia geral. 7 ed. Rio de Janeiro: Guanabara Koogan, 2004. p. 53-59.

CARVALHO, V. D. et al. Características nutritivas de fenos do terço superior e das folhas de cultivares de mandioca. Revista Brasileira de Mandioca, v. 5, n. 1, p. 63-70, 1986.

CORRÊA, A. D. et al. Remoção de polifenóis da farinha de folhas de mandioca. Ciência e Tecnologia de Alimentos, v. 24, n. 2, p. 159-164, 2004.

CORRÊA, A. D. et al. Farinha de folhas de mandioca I - Efeito da secagem das folhas sobre a atividade da linamarase. Ciências e Agrotecnologia, v. 26, n. 2, p. 368-374, 2002.

FOLCH, J.; LESS, M.; SLOANE-STANLEY, G. H. A. Simple method for isolation and purification of total lipids from animals tissues. Journal of Biological Chemistry, v. 226, n. 1, p. 407-411, 1957.

FONSECA, H. M. T. Composição química de folhas de mandioca (M. esculenta Crantz) tolerantes e suscetíveis ao estresse hídrico. Piracicaba, 1996. 90p. Dissertação - (Mestrado em Fisiologia e Bioquímica de Plantas), ESALQ.

GOLDSTEIN, J. L.; SWAIN, T. Changes in tannins in ripening fruits. Phytochemistry, v. 2, n. 4, p. 371-383, 1963.
HERVÁS, G. et al. Intoxication of sheep with quebracho tannin extract. Journal Comp. Pathology, v. 129, p. 44-54, 2003.

MADRUGA, M. S.; CÂMARA, F. S. The chemical composition of multimistura as a food supplement. Food Chemistry, v. 68, n. 1, p. 41-44, 2000.

MELO, D. S. et al. Efeitos da farinha de folhas de mandioca sobre a peroxidação lipídica, o perfil lipídico sangüíneo e o peso do fígado de ratos. Ciência e Agrotecnologia, v. 32, n. 2, p.420-428, 2007.

MIDIO, A. F.; MARTINS, D. I. Toxicologia de alimentos. São Paulo: Livraria Varela, 2000. 291p.

OKAFOR, P. N; OKOROWKWO, C. O; MADUAGWU, E. N. Occupational and dietary exposure of humans to cyanide poisoning from large-scale cassava processing and ingestion of cassava foods. Food and Chemical Toxicology, v. 40, n. 7, p. 1001-1005, 2002.

ORTEGA-FLORES, C. I. et al. Avaliação da qualidade protéica da folha desidratada de mandioca (Manihot esculenta Crantz). Sociedade Brasileira de Alimentos e Nutrição, v. 25, p. 47-59, 2003.

PADMAJA, G. Evaluation of techiques to reduce assayable tannin and cyanide in cassava leaves. Journal of Agricultural Food Chemisty, v. 37, n. 3, p. 712-716, 1989.

RAO, A. V.; KENDALL, C. W. Dietary saponins and serum lipids. Food Chemistry, v. 24, n. 5, p. 441, 1986.

RAVINDRAN, G.; RAVINDRAN, V. Changes in the nutritional composition of cassava (Manihot esculenta Crantz) leaves during maturity. Food Chemistry, v. 27, p. 299-309, 1988.

REED, J. D. et al. Condensed tannins: a factor limiting the use of cassava forage. Journal of the Science of Food and Agriculture, v. 33, p. 213-220, 1982.

REEVES, P. G.; NIELSEN, F. H.; FAHEEY, G. C. AIN-93 Purified diets for laboratory rodents: Final report of the American Institute of Nutrition ad Hoc Writing Committe on the reformulation of the AIN- 76 A rodent diet. Journal of Nutrition, v. 123, n. 11, p. 1939-1951, 1993.

ROSS, E.; ENRIQUEZ, F. Q. The Nutritive value of cassava leaf meal. Poultry Science, v. 48, n. 3, p. 846-853, 1969.

SILVA, D. J. Análise de alimentos (Métodos químicos e biológicos). Viçosa: UFV, Imprensa Universitária, 1990. 166p.

SOUSA, B. A. et al. Does prolonged oral exposure to cyanide promote hepatotoxicity and nephrotoxicity? Toxicology, v. 174, p. 87-95, 2002.

VALENCIA, Z. CHAVEZ, E. R. Lignin as a prurified dietary fiber supplement for piglets. Nutrition Research, v. 17, n. 10, p. 1517-527, 1997.

WITTHAWASKUL, P. et al. Acute and subacute toxicities of saponin mixture isolated from Schefflera leucantha Viguier. Chiang Mai. Journal of Ethno-pharmacology, v. 89, n. 1, p. 115-121, 2003.

WOBETO, C. Nutrientes e antinutrientes da farinha de folhas de mandioca (Manihot esculenta Crantz) em três idades da planta. Lavras, 2003. 82 p. Dissertação - (Mestrado em Agroquímica e Agrobioquímica), UFLA.

WOGAN, G. N.; MARLETTA, M. A. Componentes perjudiciales o potencialmente perjudiciales de los alimentos. In: FENNEMA, O. R. Química de los alimentos. 2 ed. Zaragoza: Acribia, 1993. p. $775-811$. 